\title{
The packaging design of white liquor -- grafted with ceramic cultural elements
}

\author{
$\mathrm{Na} \mathrm{Hu}{ }^{1, a}$, Qingyun Zou ${ }^{2}$ and Xing $\mathrm{Xu}^{3}$ \\ ${ }^{1}$ School of Foreign, Jingdezhen Ceramic Institute, Jingdezhen 333403, China; \\ ${ }^{2}$ School of Design and Art, Jingdezhen Ceramic Institute, Jingdezhen 333403, China; \\ ${ }^{3}$ School of Information, Jingdezhen Ceramic Institute, Jingdezhen 333403, China. \\ anala_whu@aliyun.com
}

Keywords: Grafted, ceramic culture, packaging design of white liquor.

\begin{abstract}
Up to now, the packaging design of white liquor not only lies in the visual beauty of appearance, but also weighs a lot on the exploration of its cultural connotation. As a distinguished traditional culture, the components of ceramic culture are constantly grated on to the packaging design of white liquor.From the aspect of ceramic decorative forms v process characteristics and glaze changing, this paper tries to elaborate the dramatic influence of ceramic culture on the packaging design of white liquor.
\end{abstract}

\section{The significance of graft}

Originally, graft refers to one of the vegetative reproduction method [1]. This method, with the aim of enhancing the value of the plants, selects the branches or buds of one plant, and then grafts them on to another plant, making the combination of these two into a brand new plant. As the treasure of human creation, the ceramic cultural elements have dramatically been grafted on the packaging design of white liquor, and the perfect combination arises when the ceramic elements are integrated into the forms of expression and techniques of modern packaging design [2][3]. Therefore, in its implementation of packaging function, the graft also sends out the rich connotation of the ceramic culture [4][5]. In this way, the design impresses the consumers with its cultural connotation, and the brand image of the product is due to be enhanced.

\section{Ceramics and the packaging design}

The heritage of ceramic culture. Since the world grows into a small village, more and more designers have thrown another spotlight on the distinguished Chinese cultures, and the ceramic cultural elements, which have once been popular in the western countries and now have been widely applied in the modern design, should be singled out. John Galliano, a designer for Dior, has a strong admiration for the ceramic culture, and he tries to use the elements of blue-and-white, cloisonne and the Chinese knot in his design for women shoes. His innovative design ended with a "Dior-Sinomania" worldwide, making the ceramic cultural elements be blossoming in radiant splendor.

Modern design and the ceramic culture are supplementary to each other,on the one hand, the ceramic cultural elements not only offer abundant visual expression forms to modern design for reference, but also add the profound cultural connotation to the design which could resonate with audiences spiritually and culturally; on the other hand, the concept and application of modern design are quietly penetrating into every aspect of modern life. The heritage of ceramic culture could be achieved by relying on the modern design concept and combining the ceramic cultural elements with the modern people's way of life and aesthetic demands. Therefore, it is a great way to inherit the ceramic culture by grafting the cultural elements on the modern packaging design. 
The beauty of the combination. Since the ancient times, ceramics and white liquor are inextricably linked. True, ceramics and white liquor were meant to be two different cultures, but the combination of the two cultures turns out to be so well-matched when the white liquor flows into the ceramic wares. The beauty of their "hitting on each other", from which countless ancient poets and scholars could not tear themselves away, inspires endless creation of elegant and beautiful ceramic drinking vessels.

The features of ceramics and the requirements for white liquor storage mutually bring out the best in each other, thus making the ceramic white liquor bottles (or the ceramic white liquor wares)to be the best container of white liquor package. To probe into the most amazing combination between ceramics and the package of white liquor, the following two aspects can not be ignored. From the perspective of practical material physics, to begin with, the high stability of physical chemistry of the ceramic white liquor bottles, and this high stability, which generates beneficial and healthy trace elements for human body, dues to the reason that all the white liquor bottles are made from high temperature firing. In addition, the ceramic white liquor bottles are of slight permeability but definitely nonporous(without any leakage), thus accelerates the aging effect in the process of Liquor Base Aging. Last but not least, the ceramic white liquor bottles have the features of the optical opacity and slow thermal conductivity most of the case. With the aim of avoiding the chemical reaction in white liquor brought by the light and temperature changes, the ceramic bottles creates the possibility that the white could be in the long-term storage without deterioration in a state of constant temperature. From the spiritual planes of aesthetic conception, ceramics are, first of all of great plasticity, and then with various forms of artistic expression, and thirdly of exquisite workmanship, which provide much more chances to meet the aesthetic needs of people. The ceramic white liquor bottles, not only strongly embody the culture of ceramics, but also show a deep sense of the wine culture and consequently enhance the taste and cultural connotation of white liquor.

\section{The expression patterns of this graft}

Nowadays, the sole visual stimulus of package no longer meets the aesthetic demands of people who crave more for the needs of cultural spirit. This shift of demands has already constituted the typical characteristics of the times. On the basis of the packaging design of white liquor, this shift also prompts the excavation of traditional culture, especially of the ceramic cultural element. This excavation turns out to be in the form of the graft of ceramic culture on the packaging design of white liquor, and the expressions patterns of this graft can be illustrated in the following three sides.

Ceramics could render a sense of history. In recent years, the "aged liquor", which has increasingly grown into a consumption trend, has always been highly admired by a lot of people. The consumers hold a view that it is a manifestation of high-quality life enjoyment and one' s noble social status when a person has the "aged liquor". Therefore, almost all the white liquor brands try their best to dig up the "history" of their liquor. In order to be fully exerted to aim at the "history" and "aged" strategy, the essential points of the packaging visually rest on how to represent the "sense of history".

All in all, the historic ceramics fits perfectly the new design trend. The simple and unsophisticated ceramic works remind people of the breath of the primitive farming Era, while the delicate and fine porcelains leave people in the illusion of the scene when the old artists focused on the production.

Out of question, the ceramic bottles injected a fresh breath into the market where the plastic, glass and other synthetic materials of wine bottles are made, and render the "sense of history" to the products at the same time. Therefore, a variety of classic styles, for instance, the Meiping of Ming dynasty ( a vase which is narrow out-curled mouthed, short-necked and broad-shouldered), the garlic-head-shaped vase(a vase which was made in Jingdezhen Kiln in the Qing dynasty), the globular shape vase(which is exclusively made by the Jingdezhen Imperial Kiln in the Qing dynasty) and the the Bronze Vase Named"Yu Hu Chun"---a pear-shaped vase with a flared lip, are all typically produced by grafting the ceramic cultural elements onto the packaging design of white liquor. 
The craft-work enriches the nobility of products. The ceramic process provides the technical support for ceramic/porcelain decoration, in this way, it also greatly enriches the performance of ceramic techniques and makes the ceramic products seem to be more precious with the even finer techniques. The ceramic bottles, which would have been containers of the white liquor, have already undergone the magnificent transformation. This transformation, from the plain container into an exquisite work of arts, is completed by employing the new design on the shapes of wine vessels, adopting the traditional techniques of prime technology and using the ceramic crafting techniques including blue and white, pastels, Tou-ts'ai and enamels. Without a doubt, the ceramic bottles are no longer containers of white liquor but art works which are deeply loved and favored by a large number of customers.

With the aim of enriching the nobility of the products inside, all kinds of techniques are deliberately employed on the packaging design of white liquor, and Sichuan Tuopai Shede Wine could be an excellent example to illustrate this point. One of the Shede Wine Series, the Supreme Shede, whose package is designed in the precious National Porcelain of "blue-and-white with gold-painted design", uses the shape of the globular shape vase for reference. To its credit, the packaging design of this extremely expensive wine did not cling to the classic appearance but did function processing to some of its parts, consequently, this innovative design strengthens the aesthetic feeling and also pays close attention to the functional requirements of the bottles. The bottles, for one thing, are shaped in continuation of the traditional craft---the blue and white techniques; for another, are covered with glazes of handmade relief on gold. The gold, with its fine and delicate craftsmanship, highly highlights the luxury of the bottle/vessel and extensively extends the nobility of the wine by outside and then inside.

The glaze inspires thoughts. The high temperature colored-glaze porcelain , which is regarded as The Four Famous Porcelains together with the Blue-and white wares, the Fencai porcelain (famille rose porcelain) and the rice-pattern decorated porcelain, is ought to be hard in texture and jade-like in color. No wonder it once has compared to be "as green as the water in the early spring, and as red as the morning clouds in the rising sun" by scholars of home and abroad, because no one could resist the charm of its ample colors and crystal transparent body. Generally, the Colored-glaze porcelain can be classified into two types, the pure color glaze (the glaze is all of one color) and the color glaze (the glaze of mixed colors), of which the former is featured as "all one color, pure, jade-like and shining" and is also considered to be one of a kind that fully represents the beauty of "noble simplicity and silent greatness" . Ranging from the different glazes to the different aesthetic feelings, the inspired thoughts are eventually distinctive, for example, there could have been the nobility of $\mathrm{Ji}$ Red(sacrificial red glaze), the solemnity of Ji Blue (sacrificial blue glaze) or the elegance of green glaze. The color glaze, which is called as the glaze of mixed colors above in this paper, is said to be the accidental results of fambe---the changes in kiln. However, the variety of colors and uncertainty of the changes make the color glaze covered with a mysterious veil as long as there could be pale and light colors or there could be the bold and heavy colors. The realm of aesthetics, which occurs in the fambe-- the changes in kiln, could have aroused people's imagination and left them obsessed with the beauty of changes.

With the increasingly raised aesthetic ability of people, the high temperature colored-glaze porcelain, which has been widely applied to ceramic decorations, is highly loved and favored in the white liquor package. With a brand new concept and an unique innovation, the elements of this glaze have been grafted on the white liquor package. This graft, which aims at impressing people with the beauty of glazes, tries to guide the identification of the wine and enrich the imagination of wine with the aid of imaginations caused by the changing glazes. The "National Celluar 1573 • Celadon Bottle " is a typical case in point that the glaze inspires thoughts: the sky-green entire body leaves people in the pure and fresh associations while the continuous waves carved on the bottle indicate the soft taste of the wine. 


\section{Conclusion}

To sum up, the graft, which is supposed to combine the traditional ceramic elements with the packaging design of white liquor, not only strengthens the the cultural connotation of the products, but also enriches the ideas of designing. Being intended to transfer the consumers' favor of the ceramic cultural elements to the white liquor itself, the graft successfully increases the additional value and enhances the brand image of the white liquor.

\section{References}

[1] Chen Qi, Ceramic Arts and Process, Higher Education Press, Beijing, 2005.

[2] Chen Yuqian. A Probe into the Concept and Characteristics of Ceramic Culture. Journal of Nanjing Arts Institute(Fine Arts \& Design), 4(2010) 93-97.

[3] He Bingqin. On the Promote and Heritage of Ceramic Culture. Chinese Chuangzuo Ping Tan, 1(2012).

[4] Xu Liaoyuan, Impression-- the report of creativity in a decade in Pusu Tang, Sichuan Fine Arts Press, 2004.

[5] Yihua He, Ceramic Sichuan Liquor Set Design,A Form of Meaning-Sichuan Liquor Ceramic Package Design Rooting in Chinese Traditional Culture, China Ceramics, 2014. 